\title{
Catatan Editor: Peran psikologi sosial dalam mengatasi dampak pandemi COVID-19
}

\author{
Mirra Noor Milla* \\ Fakultas Psikologi, Universitas Indonesia, Depok, Jawa Barat
}

Catatan Editor Jurnal Psikologi Sosial (JPS) edisi Februari 2022 sedikit berbeda. Hal ini disebabkan pada tahun 2022 ini JPS hadir dengan sejumlah perubahan. Dr. Bagus Takwin, M.Hum., yang selama ini mengawal JPS sebagai Ketua Dewan Editor dari tahun 2017 hingga Desember 2021, saat ini telah mengemban amanah baru sebagai Dekan Fakultas Psikologi Universitas Indonesia 2021-2025. Saya sebagai pengganti Ketua Dewan Editor merasa perlu menyampaikan ucapan terima kasih secara terbuka dalam tulisan catatan editor ini.

Segenap tim redaksi mengucapkan terima kasih atas dedikasi, waktu, tenaga dan pikiran yang telah dicurahkan selama ini. Dr. Bagus Takwin telah membantu 'menghidupkan' kembali JPS yang sempat vakum selama beberapa tahun, dan saat ini telah membawa JPS menjadi salah satu jurnal Psikologi di Indonesia yang terakreditasi SINTA 2. Selanjutnya saya, yang saat ini selain sebagai staf pengajar di Fakultas Psikologi UI juga sebagai Ketua Ikatan Psikologi Sosial - HIMPSI, bersama tim editor JPS yang baru, akan meneruskan kerja Dr. Bagus Takwin dan menyelesaikan agenda-agenda JPS selaras dengan visi dan misi dari dua Lembaga penerbit JPS, yaitu Fakultas Psikologi Universitas Indonesia dan Ikatan Psikologi Sosial (IPS).

Pada Edisi Februari 2022 ini, JPS masih mengusung sejumlah naskah dengan tema pandemi COVID-19. Selain disebabkan masih banyaknya ruang eksplorasi kajian untuk topik ini (Bavel dkk., 2020), permasalahan pandemi dan dampak yang ditimbulkan juga masih menyisakan sejumlah masalah yang memerlukan sumbangsih pemikiran dari akademia. Sumbangsih tersebut diperlukan salah satunya sebagai sumber data saintifik untuk pengambilan kebijakan. Permasalahan well-being, penggunaan internet dan konteks sosial budaya yang khas di Indonesia, merupakan tiga tema utama yang menjadi pilihan editor untuk edisi kali ini.

Ketiga topik tersebut dianggap penting karena dinilai relevan menjawab berbagai permasalahan yang muncul selama hampir dua tahun kita menjalani hidup bersama dalam ketidakpastian karena pandemi COVID-19. Mulai dari pembatasan sosial yang berdampak pada permasalahan pemenuhan kebutuhan relasi sosial dan well-being (van Breen, 2021), mening- katnya penggunaan media online pada berbagai kelompok usia termasuk anak usia dini (Kamaşak, 2021). Kondisi ini juga dimanfaatkan oleh kelompok-kelompok ekstremis sehingga dapat meningkatkan ancaman radikalisme (Davis, Wu \& Frank, 2021). Selain itu kita juga dipaksa menghadapi tantangan adaptasi fisik, ekonomi, sosial hingga politik selama pandemi. Tidak dapat dihindari pandemi COVID-19 telah mengubah berbagai aspek kehidupan kita (Han, dkk., 2021; Stroebe, 2021; Resta, 2021; Romano, 2021). Dunia tidak lagi sama sebelum dan sesudah pandemi COVID-19. Selain ketiga hal tersebut, permasalahan sosial terkait dampak pandemi masih banyak yang belum sepenuhnya dapat dijelaskan, sehingga dalam beberapa edisi ke depan, topik terkait pandemi COVID-19 masih akan menghiasi JPS.

Selain masih relevannya topik pandemi dalam kajian Psikologi Sosial saat ini, pilihan terhadap naskah yang bertema pandemi COVID19 ini, juga didasarkan pada visi dan misi JPS. JPS memiliki misi berkontribusi dalam mengembangkan produksi Ilmu Pengetahuan, khususnya dalam bidang kajian Psikologi Sosial melalui publikasi hasil-hasil studi primer riset-riset dasar untuk menjawab isu-isu teoritis, maupun hasil riset yang dapat menjawab pemecahan masalah sosial, baik yang memiliki implikasi praktis langsung maupun yang dapat berkontribusi pada kebijakan publik.

Pada tahun 2022, direncanakan JPS akan mengundang para peneliti Psikologi Sosial di Indonesia untuk memberikan kontribusi tulisan dari hasil riset dalam isu spesial dengan topik "Aplikasi Psikologi Sosial: Kontribusi Psikologi Sosial dalam Kebijakan Publik". Spesial isu tersebut dimaksudkan untuk memberikan sumbangan pemikiran bagi pengambil kebijakan dalam upaya menjawab berbagai masalah sosial yang terjadi di Indonesia. Selain itu, riset-riset topik aplikasi psikologi sosial juga merupakan topik penting selain riset-riset pengembangan teori dasar. Dari hasil hasil riset aplikasi Psikologi Sosial, dapat diharapkan perkembangan kajian dan penelitian Psikologi Sosial di Indonesia akan semakin relevan dan tidak terasing dari permasalahan di lapangan yang kita hadapi. 
Selain isu spesial yang diharapkan dapat mendorong diseminasi hasil-hasil riset di topik khusus yang dinilai penting, JPS juga akan terus berupaya meningkatkan kualitas publikasi, diantaranya dengan memperbaharui tim editorial, tim reviewer dan tim admin. Sehingga kualitas publikasi JPS dapat terus ditingkatkan dan kesinambungan penerbitan dapat selalu dipertahankan.

Tidak lupa terima kasih saya ucapkan kepada segenap tim editor, para reviewer dan tim admin yang selama ini telah bekerja keras mengupayakan JPS agar dapat selalu terbit tepat waktu dan menjaga kualitas publikasi di JPS, sehingga JPS menjadi salah satu media publikasi yang dijadikan referensi ilmiah bagi para mahasiswa, akademisi dan peneliti di bidang Psikologi Sosial di Indonesia.

\section{Referensi}

Bavel, J. J. V., Baicker, K., Boggio, P. S., Capraro, V., Cichocka, A., Cikara, M., Crockett, M. J., Crum, A. J., Douglas, K. M., Druckman, J. N., Drury, J., Dube, O., Ellemers, N., Finkel, E. J., Fowler, J. H., Gelfand, M., Han, S., Haslam, S. A., Jetten, J., ... Willer, R. (2020). Using social and behavioural science to support COVID19 pandemic response. Nature Human Behaviour, 4(5), 460-471. https://doi.org/10.1038/s41562-0200884-z

Davies, G., Wu, E., \& Frank, R. (2021). A Witch's Brew of Grievances: The Potential Effects of COVID-19 on Radicalization to Violent Extremism. Studies in Conflict and Terrorism, $\quad 0(0), \quad 1-24$. https://doi.org/10.1080/1057610X.2021. 1923188

Han, Q., Zheng, B., Agostini, M., Bélanger, J. J., Gützkow, B., Kreienkamp, J., Reitsema, A. M., van Breen, J. A., Leander, N. P., Abakoumkin, G., Abdul Khaiyom, J. H. B., Ahmedi, V., Akkas, H., Almenara, C. A., Atta, M., Bagci, S. C., Basel, S., Kida, E. B., Buttrick, N. R., ... Zúñiga, C. (2021). Associations of risk perception of COVID-19 with emotion and mental health during the pandemic. Journal of Affective Disorders, 284(October 2020), 247-255. https://doi.org/10.1016/j.jad.2021.01.049

Kamaşak T, Topbaş M, Ozen N, et al. An Investigation of Changing Attitudes and Behaviors and Problematic Internet Use in Children Aged 8 to 17 Years During the COVID-19 Pandemic. Clinical Pediatrics. 2022;61(2):194-205.

https://doi.org/10.1177/000992282110 65842
Resta, E., Mula, S., Baldner, C., Santo, D. Di, Agostini, M., Bélanger, J. J., Gützkow, B., Kreienkamp, J., Abakoumkin, G., Khaiyom, J. H. A., Ahmedi, V., Akkas, H., Almenara, C. A., Atta, M., Bagci, S. C., Basel, S., Kida, E. B., Bernardo, A. B. I., Buttrick, N. R., ... Leander, N. P. (2021). 'We are all in the same boat': How societal discontent affects intention to help during the COVID-19 pandemic. Journal of Community and Applied Social Psychology, August, 1-16. https://doi.org/10.1002/casp.2572

Romano, A., Spadaro, G., Balliet, D., Joireman, J., Lissa, C. Van, Jin, S., Agostini, M., Bélanger, J. J., Gützkow, B., Kreienkamp, J., Leander, N. P., Abakoumkin, G., Khaiyom, J. H. A., Ahmedi, V., Akkas, H., Almenara, C. A., Atta, M., Bagci, S. C., Basel, S., ... Zúñiga, C. (2021). Cooperation and Trust Across Societies During the COVID-19 Pandemic. Journal of Cross-Cultural Psychology, 52(7), 622-642. https://doi.org/10.1177/0022022120988 913

Stroebe, W., vanDellen, M. R., Abakoumkin, G., Lemay, E. P., Schiavone, W. M., Agostini, M., Bélanger, J. J., Gützkow, B., Kreienkamp, J., Reitsema, A. M., Abdul Khaiyom, J. H., Ahmedi, V., Akkas, H., Almenara, C. A., Atta, M., Bagci, S. C., Basel, S., Kida, E. B., Bernardo, A. B. I., ... Muhammad, H. (2021). Politicization of COVID-19 healthprotective behaviors in the United States: Longitudinal and cross-national evidence. PLoS ONE, 16(10), 1-22. https://doi.org/10.1371/journal.pone.025 6740

Van Breen JA, Kutlaca M, Koç Y, Jeronimus BF, Reitsema AM, Jovanović V, Agostini M, Bélanger JJ, Gützkow B, Kreienkamp J, Abakoumkin G, Khaiyom JHA, Ahmedi V, Akkas H, Almenara CA, Atta M, Bagci SC, Basel S, Berisha Kida E, Bernardo ABI, Buttrick NR, Chobthamkit P, Choi HS, Cristea M, Csaba S, Damnjanovic K, Danyliuk I, Dash A, Di Santo D, Douglas KM, Enea V, Faller DG, Fitzsimons G, Gheorghiu A, Gómez Á, Hamaidia A, Han Q, Helmy M, Hudiyana J, Jiang DY, Kamenov Ž, Kende A, Keng SL, Kieu TTT, Kovyazina K, Kozytska I, Krause J, Kruglanski AW, Kurapov A, Lantos NA, Lemay EP Jr, Lesmana CBJ, Louis WR, Lueders A, Malik NI, Martinez A, McCabe K, Mehulić J, Milla MN, Mohammed I, Molinario E, Moyano M, Muhammad H, Mula S, Muluk H, Myroniuk S, Najafi R, Nisa CF, Nyúl B, O'Keefe PA, Olivas Osuna JJ, Osin EN, Park J, Pica G, Pierro A, Rees J, Resta E, Rullo M, Ryan MK, Samekin A, Santtila P, Sasin E, Schumpe 
BM, Selim HA, Stanton MV, Sultana S, Sutton RM, Tseliou E, Utsugi A, van Lissa CJ, van Veen K, vanDellen MR, Vázquez A, Wollast R, Wai-Lan Yeung V, Zand S, Žeželj IL, Zheng B, Zick A, Zúñiga C, Leander NP. Lockdown Lives: A Longitudinal Study of Inter-Relationships Among Feelings of
Loneliness, Social Contacts, and Solidarity During the COVID-19 Lockdown in Early 2020. Pers Soc Psychol Bull. 2021 Aug 25:1461672211036602.

https://doi.org/10.1177/014616722110

36602. Epub ahead of print. PMID: 34433352 . 